\title{
Juggling Roles, Experiencing Dilemmas: The Challenges of SSH Scholars in Public Engagement
}

\author{
Jantien Willemijn Schuijer (D). \\ Jacqueline Broerse • Frank Kupper
}

Received: 16 August 2020 / Accepted: 15 July 2021 / Published online: 18 August 2021

(C) The Author(s) 2021

\begin{abstract}
The progressive introduction of emerging technologies, such as nanotechnology, has created a true testing ground for public engagement initiatives. Widespread experimentation has taken place with public and stakeholder dialogue and inclusive approaches to research and innovation (R\&I) more generally. Against this backdrop, Social Science and Humanities (SSH) scholars have started to manifest themselves differently. They have taken on new roles in the public engagement field, including more practical and policy-oriented ones that seek to actively open the R\&I system to wider public scrutiny. With public engagement gaining prominence, there has been a call for increased reflexivity among SSH scholars about their role in this field. In this paper, we study our own roles and stakes as SSH scholars in a European-funded public engagement project on responsible nanotechnology. We introduce a general role landscape and outline five distinct roles (engaged academic, deliberative practitioner, change agent, dialogue capacity builder, and project worker) that we-
\end{abstract}

\footnotetext{
J. W. Schuijer $(\bowtie)$

Lorentz Center, Science Faculty, Leiden University,

Leiden, Netherlands

e-mail: schuijer@lorentzcenter.nl

J. Broerse · F. Kupper

Athena Institute, VU University, Amsterdam, Netherlands

e-mail: j.e.w.broerse@vu.nl

F. Kupper

e-mail: f.kupper@vu.nl
}

as SSH scholars-inhabited throughout the project. We discuss the synergistic potential of combining these five roles and elaborate on several tensions within the roles that we needed to navigate. We argue that balancing many roles requires explicit role awareness, reflexivity, and new competencies that have not been examined much in the public engagement literature so far. Our role landscape and exemplification of how it can be used to reflexively study one's own practices may be a useful starting point for scholars who are seeking to better understand, assess, or communicate about their position in the public engagement field.

Keywords SSH scholars · Role dilemmas $\cdot$ Role integration · Public engagement · Reflexivity · Responsible research and innovation

\section{Introduction}

Since the 1990s, we have witnessed a rise in public engagement ${ }^{1}$ with science and technology governance. An extensive body of public engagement literature has emerged and widespread experimentation has taken place with deliberative approaches that "open up" science and technologies to new voices

\footnotetext{
${ }^{1}$ Note that we use the term "public engagement" to refer to engagement activities with general publics and/or stakeholders. It includes activities that have strong/direct or weak/indirect connections to actual policy-making processes.
} 
and perspectives [1-4]. The growing interest in public engagement has been fueled by several converging developments, including (1) public controversies concerning technologies such as genetic modification and nuclear power, (2) a growing interest in transdisciplinary modes of knowledge production, and (3) socioscientific critique on the "knowledge deficit" that is often attributed to laypeople in discussions on science and technology $[5,6]$. In the last two decades, attempts have been made to move public engagement "upstream" $[1,7]$. The emerging field of nanotechnol$o g y^{2}$ has played a significant role here, serving as a true testing ground for the involvement of stakeholders and publics at a very early stage of development when adaptation of research and innovation (R\&I) trajectories is still possible $[4,7,8]$.

The growth of this public engagement is grounded in a call for a new relationship between science and society-one that acknowledges the value of a broader range of experiences and knowledge types when dealing with complex issues surrounding technology [5]. This transformative ideal that moves toward democratization of the R\&I system has been integrated into various policy approaches over time, including anticipatory governance $[9,10]$, real-time Technology Assessment (TA) [11], constructive TA, and, more recently, Responsible Research and Innovation (RRI) [12-15]. These approaches specifically promote better alignment between the drivers and purposes of technology development on the one hand and the needs, concerns, and values of societal actors on the other.

\section{The Many Roles of the SSH Scholar}

Scholars in the social sciences and humanities (SSH) have played a prominent role in public engagement's "coming of age" [2]. Yet the character of their contribution and their role in the field have changed over time. Delgado et al. [2] clearly describe the evolution of the SSH scholar in research and innovation since the 1990s as moving from (1) focusing on descriptiveanalytical studies of science and technology practices to moving toward the successive integration of (2) more normative approaches to (critically) commenting on science policy, (3) approaches that focus on the

\footnotetext{
${ }^{2}$ Note that for readability purposes, we use the term "nanotechnology" throughout this paper to refer to the broader spectrum of nanosciences and nanotechnologies.
}

development of practical tools and strategies to shape interactions between science and society, and (4) social science intervention, that is, testing these tools and strategies as engagement practitioners in the field. This last step implies that SSH scholars-who are working from assumptions grounded in deliberative ideals and are inspired by theories arising from Science and Technology Studies, policy science, TA, and ethics-also take on practical roles, such as organizers and facilitators of events that aim to encourage public and stakeholder dialogue $[2,16]$. Today's SSH scholar therefore has a strong normative stance and moves beyond the mere study of R\&I practices, also advocating and enacting more inclusive forms of governance in science and technology.

We cannot solely attribute these role changes to the intrinsic desire of individual SSH scholars to take on new positions in the field. Instead, role making and taking of SSH scholars should be understood as a "co-productive" process [17]. Historical role shifts and role preferences should be understood as entangled with (changes in) norms, discourses, and structural and material conditions in academic practice and science and innovation policy more generally. Indeed, the choice to adopt - or not to adopt - a particular role depends on dogmas in one's (sub)discipline (e.g., are action-oriented roles accepted by peers?), one's embedment in certain networks, university policies and academic reward systems, one's own career perspectives (inside or outside academia), dependency on superiors, and-evidently-funding opportunities $[18,19]$. The increased availability of European funds for (action-oriented) work on socio-technical integration and public engagement over the past decades, in combination with heightened competition levels and decreased state funding for the $\mathrm{SSH}$, are surely forces that dynamically interrelate with the choice of scholars to adopt roles that are more action-oriented. In that sense, the role changes we have witnessed over time have also been encouraged institutionally.

\section{The Call for Role Reflexivity}

With the public engagement field becoming more mature and professionalized-Chilvers [20] even refers to it as an industry on its own-there have been calls for more reflexivity among SSH scholars concerning the role(s) that they play in this field [20-22]. In Science and Technology Studies and science 
policy research, various attempts have been made to engage in such reflection by creating and contrasting all kinds of SSH role typologies, which range from "ironists, reformers, and rebels" [21] to "organizers, observers, and participants" [23]. These typologies clearly demonstrate the existing diversity in the activities, approaches, and orientations of SSH scholars in the public engagement field. However, many of the studies have employed macro perspectives and therefore fail to show (1) how specific roles become integrated into the messy practice of public engagement projects, (2) what specific role synergies and conflicts result from such integration, and (3) how these synergies and conflicts affect the process qualities of public engagement initiatives. We consider such knowledge and reflexivity crucial, particularly at a time when many publicly funded engagement projects rely heavily on the versatile role identities of the SSH scholar.

\section{A Reflexive Study on Role Conflicts and Synergies}

In this paper, we aim to understand the role synergies and role conflicts that SSH scholars may encounter when integrating multiple roles in their public engagement-related work, particularly in normative contexts that are focused on (policy) intervention. We will do so by reflexively studying our own position and stakes in a European RRI project called NANO2ALL, which focuses on the topic of nanotechnology. We consider this single-case study approach particularly suitable to move beyond classifying and distinguishing general SSH role typologies-as has been done before us - and to allow for a deeper and more nuanced exploration of the struggling with roles in relation to in situ requirements. Our reflexive account takes seriously the trade-offs we encountered, the confusion that we felt, and the doubts and considerations that we had within the context of our project, as it was in these instances that our awareness was raised to underlying role synergies and conflicts. Although internal discomfort of scholars often remains neglected in research accounts, we are convinced that it deserves articulation and exploration. In our case, it may tell us something about the complexity of role taking and making in the current institutional landscape and introduce valuable questions that scholars should pose about themselves and the broader institutional context in which they operate.
In this paper, we first introduce the NANO2ALL project (i.e., "the empirical setting") and then we refer to the existing literature to sketch out the role landscape that we inhabited and describe five distinct role typologies that we navigated throughout the project. After elaborating on the resulting role synergies and conflicts, we use the discussion section to reflect on the implications of our insights for the maturing engagement field and the SSH scholar's role within it. Inhabiting a multitude of roles can be confusing for SSH scholars and the people they collaborate with $[24,25]$. In this paper, we hope to provide a starting point for those scholars who seek to better understand and communicate their own position in the public engagement field, without eschewing questions about the relevance of institutions and structural conditions in the making and testing of their roles.

\section{Empirical Setting: Case Description}

The NANO2ALL project was a 3.5-year Coordination and Support Action project "funded under the European Union's Horizon 2020 Research and Innovation programme, and aimed at contributing to the establishment of RRI policy and governance of nanotechnologies" [26]. The main output of the project was focused on the implementation of supporting activities, such as the organization of (policy-oriented) dialogues, outreach events, the setting up of professional networks and infrastructures, etc. NANO2ALL's project consortium consisted of 11 collaborating partners from diverse fields (i.e., ranging from technology platforms and nanoscientists to consultancy companies and journalists' associations). The project also collaborated with several third parties, for example six science centers and (informal) learning institutions across Europe. Two of the authors of this paper, $\mathrm{JS}^{3}$ and $\mathrm{FK}^{3}$, actively collaborated in this project as university-affiliated SSH scholars. Author $\mathrm{JB}^{3}$ was involved with their work from a distance, providing advice and stimulating reflection. Box 1 sets out a general description and the core principles of RRI, a concept central to the project.

\footnotetext{
3 JS stands for first author of this paper, FK stands for last
} author of this paper, JB for second author of this paper. 
Table 1 Rough overview of main project activities

\begin{tabular}{ll}
\hline Activity cluster & List of activities \\
\hline $\begin{array}{l}\text { Developing a com- } \\
\text { mon understand- }\end{array}$ & - Sketching the current nanoscience and nanotechnologies landscape \\
ing & - Identifying the best practices of RRI in nanoscience and nanotechnologies \\
& mation materials \\
Dialogues & - Organizing citizen dialogues in 6 countries \\
& - Organizing national multistakeholder dialogues in 6 countries \\
& - Organizing a European multistakeholder dialogue in Brussels, resulting in interim policy recommendations \\
& for the European Commission \\
Toward a roadmap & - Combining project insights and gathering additional information to construct a roadmap that aims to increase \\
& societal engagement in nanoscience and nanotechnologies \\
& - Organizing a roadmap validation symposium in Brussels
\end{tabular}

Box 1 Responsible Research and Innovation (RRI)

\section{General description}

RRI is a broad concept that has gained particular prominence in European innovation policy during the last few years, because it has been used in the Horizon 2020 program [15, 27]. The concept revolves around the collective responsibility to steer research and innovation toward desirable and acceptable ends [15, 27].

\section{Core principles}

Although the term RRI still lacks conceptual specificity and can be "translated" in various ways, several core principles can be extracted from the literature [27, 28]:

- Inclusion of a broad range of (societal) actors and publics throughout all stages of the R\&I process

- Anticipation of potential risks and broader societal impacts of new technology

- Reflection on the beliefs and values that shape our perception of and activities in R\&I processes

- Responsiveness to changing circumstances and societal perspectives by truly changing our course of action

The project consisted of several activities that revolved around mutual learning and dialogue between diverse stakeholders from industry and civil society organizations, citizens, policy makers, academics, intermediaries, etc. One of the main outputs that the project was working toward was a set of recommendations that would be presented as a roadmap for both European and national policymakers on how to implement RRI with respect to nanoscience and nanotechnologies and how to better integrate societal needs, concerns, and values into R\&I processes. The project consisted of three core activity clusters: (1) developing a common understanding of nanotechnology developments and RRI practices, (2) establishing citizen and multistakeholder dialogues, and (3) developing a roadmap that aimed to increase societal engagement in nanoscience and nanotechnologies. Table 1 presents the components of these activity clusters in more detail.

As SSH scholars, we-JS and FK-were most heavily involved in the "dialogues" activity cluster of the project. This activity cluster focused on three rounds of dialogue: (1) a round of citizen dialogues in France, Israel, ${ }^{4}$ Italy, Poland, Spain, and Sweden,

\footnotetext{
${ }^{4}$ Note that although Israel is located outside of the European Union, it is permitted to apply for European Union funding.
} 
Fig. 1 Overview of dialogue rounds. FR France, $I S$ Israel, $I T$ taly, $P L$ Poland, $S P$ Spain, $S W$ Sweden
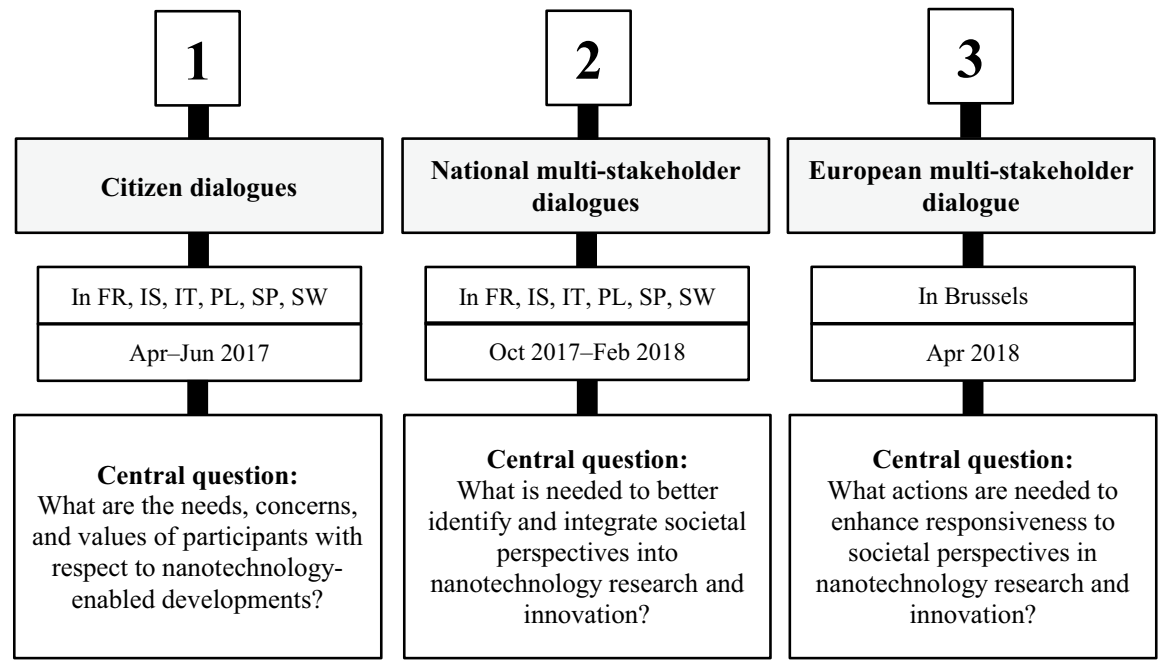

(2) a round of national multistakeholder dialogues in those same countries, and (3) a European multistakeholder dialogue event in Brussels. We were in charge of designing the overall dialogue methodology and of both monitoring and analyzing the dialogue process and outcomes. Local science centers and (informal) learning institutions ${ }^{5}$ hosted the first two dialogue rounds, and we trained their staff in the developed dialogue methodology. We hosted and facilitated the third dialogue round in Brussels ourselves, receiving support from three project partners and three additional SSH colleagues from our own research department. We were invited to submit the outcomes of this third dialogue round to the European Commission as an interim set of recommendations for an internal policy note on governance.

As Fig. 1 shows, each of the three dialogue rounds focused on a slightly different question. Whereas the citizen dialogues centered on letting citizens explore the values, needs, and concerns that are important to them in relation to a specific nanotechnology-application field (i.e., nanomedicine, nanotechnology-enabled brain-machine interfaces, nanotextiles ${ }^{6}$ ), both the national and the

\footnotetext{
5 All six institutions were members of the European platform for science centers and museums. For convenience, we will refer to these institutions as "science centers" throughout the rest of the paper.

6 These application fields were chosen in close collaboration with the local science centers themselves, taking into account (1) the national research context, (2) the current public discourse in the country, and (3) the institutions' connections in the field.
}

European multistakeholder dialogues focused more explicitly on the concept of RRI and the notion of public engagement. The latter two forms of dialogue can thus be characterized as engagement events about public engagement in nanotechnology. Although the three NANO2ALL dialogue rounds did not directly build on each other, the outputs of one dialogue round often fed into a component of the subsequent dialogue round (e.g., needs, concerns, and values identified by citizens in the first round of dialogue were used to open the conversation about public engagement in the second round of dialogues). In addition, each of the dialogues in the second and third rounds was attended by one or more participants of the previous round(s). Table 2 summarizes the specific dialogue-related activities in which we were involved throughout the project as SSH scholars ${ }^{7}$.

\section{Role Framework}

In order to disentangle the various role synergies and role conflicts that we experienced as SSH researchers in a normative intervention-oriented context, we constructed a framework that depicts the role landscape in which we found ourselves working throughough our RRI project (Fig. 2). When we were constructing

\footnotetext{
${ }_{7}$ Note we received support from other project partners in various activities.
} 
Table 2 Our main activities in the project as SSH scholars

- Developing dialogue formats and materials (for all three dialogue rounds)

- Training the staff at science centers and informal learning institutes in dialogue methodology for rounds 1 and 2

- Organizing and facilitating the European dialogue (round 3)

- Combining dialogue data and analyzing and reporting on dialogue outcomes

- Writing interim policy recommendations based on the results of the European dialogue (round 3)

- Monitoring and evaluating the dialogue process

- Disseminating dialogue materials among those interested in the field, which included visits to academic and practitioner conferences to present our dialogue approach and methods

- Publishing (scientific) papers on dialogue methods, processes, and/or content (not as a project deliverable, but as part of the communication strategy of the project)

- Providing supportive assistance in other activity clusters of the project if needed (e.g., helping out with crafting the roadmap)

the framework, we drew on literature about the role of SSH in (1) public engagement and R\&I democratization [20, 21, 24, 25] and (2) Technology Assessment [29]. We also borrowed from literature in the fields of transdisciplinary and process-oriented sustainability science [30, 31]. Just like RRI, this field has a strong normative and transformative character and therefore produces similar role patterns for SSH scholars to the ones we found in our public engagement work. Within our framework's general landscape, we have depicted the specific roles that we as authors of this paper have inhabited in the NANO2ALL project. These roles are "ideal-types" [31] in the sense thatin practice - they rarely existed in isolation. As typologies, though, they do help us to more clearly define why certain role synergies and tensions were experienced. The role that typologies and their distribution play across the landscape shows that the SSH scholar in public engagement cannot be captured as having only one role identity, but instead operates on different spectra of role characteristics.

\section{The Role Landscape}

Chilvers [20] criticized SSH scholars' tendency to describe their role within the public engagement field as either being critical-distant or pragmatic-supportive. We agree with Chilvers that such a dichotomous distinction does not do justice to the role complexities we encounter in public engagement practice. These complexities can be assessed better if we assume dynamic positioning in a role landscape. We therefore created a role landscape that has two different axes (see Fig. 2), which will be clarified in more detail below.
The first axis relates to the type of contribution that an SSH scholar aspires to make. At one end of the spectrum, we find the SSH scholar who primarily aspires to contribute to academic reflection, and therefore, deliberately remains distant from getting involved in the actual policy and political processes of the R\&I system [20, 21, 29]. He or she may, for instance, describe, analyze, or comment on public engagement processes, mainly to stimulate long-term (critical) reflection. At the other end of the spectrum, we find the SSH scholar who actively seeks to influence policymaking through public engagement and who does not avoid political involvement either. $\mathrm{He}$ or she may, for example, host or participate in policyoriented engagement events or contribute to shaping RRI policies in specific branches of R\&I. Although a strong focus on academic reflection may thwart having a direct impact on real-world problems, a strong focus on policy and political action may risk losing one's critical distance [20].

The second axis relates to the character of the change that is strived for. Here we distinguish between incremental and radical change. In the context of our public engagement work, this "change" specifically refers to the democratization of the R\&I system. ${ }^{8} \mathrm{We}$ consider this distinction in the framework particularly relevant because of the pervasive ambiguity about the degree of transformation that is strived for when using RRI and public engagement approaches $[6,15]$.

\footnotetext{
$\overline{8}$ The direction of change depends on the context of the work. In our case, democratization of the R\&I system was central to our work. In process-oriented sustainability science, for example, the change on this axis would-probably-relate to $\mathrm{X}$ becoming more sustainable.
} 


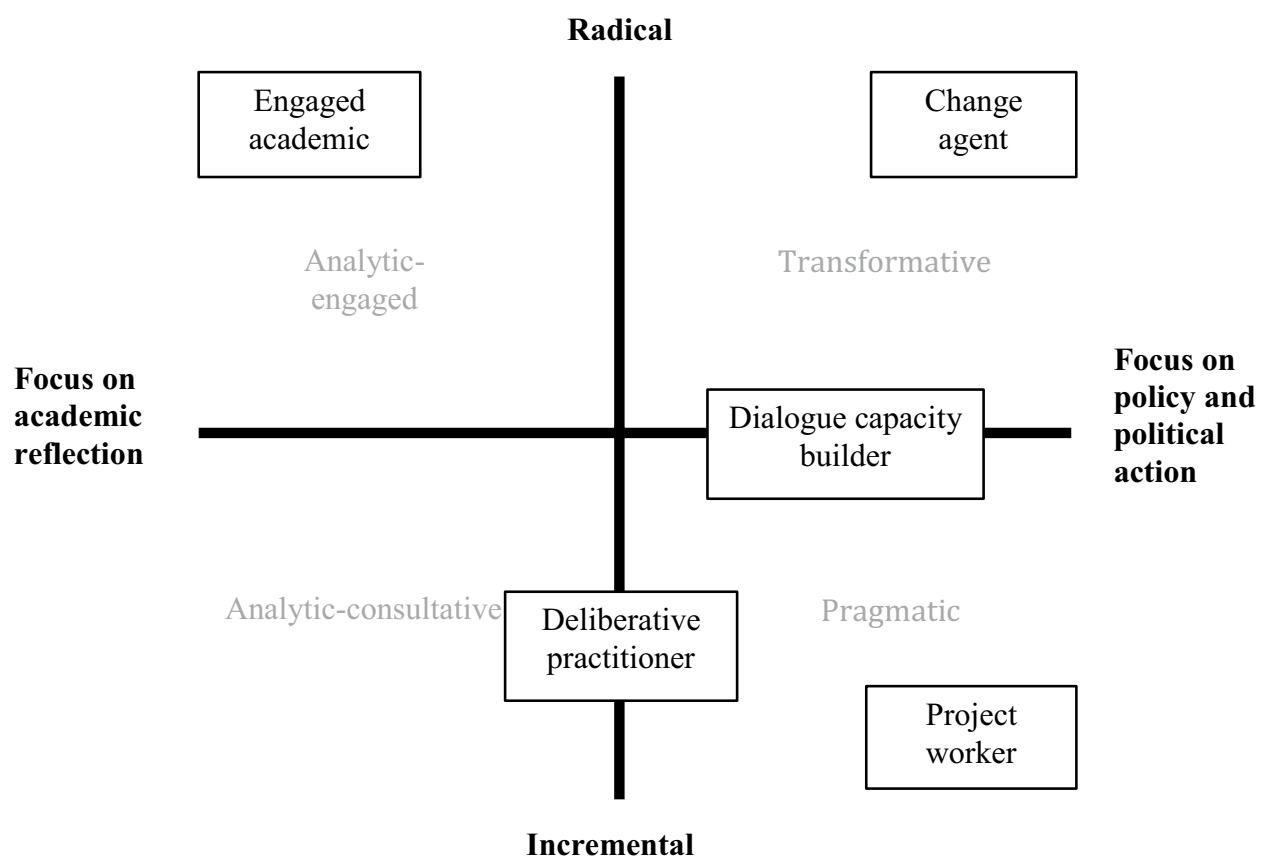

Fig. 2 Role framework

For example, while some actors-including many SSH scholars-interpret RRI as a radically new and more inclusive way of governing science and technology, others favor a conceptualization that sticks as closely as possible to current understandings of science and technology and their governance practices [32]. In our role framework, the incremental end of the change axis thus represents a focus on pragmatic changes toward democratization, made gradually, that can be achieved within the current R\&I governance system [20, 21]. An SSH scholar with such a focus may, for example, work with solution-oriented research questions that are framed within the scope of the existing governance system [24] or focus on the development and optimization of engagement formats that can be integrated into current system structures. The other end of the spectrum represents a more radical and ambitious take on change that leads to democratization; it implies a focus on challenging and reimagining the entire R\&I (governance) system as it is today [20, 21]. SSH scholars with this more radical focus may, for instance, provide scholarly critique on the current system or advocate alternative systems [20]. SSH scholars who strongly focus on incremental change may risk overlooking bigger questions that are important to raise. Being too radical, on the other hand, may risk coming across as naïve and not taking into account real-world structures and barriers that need to be dealt with to bring about change [20]. Evidently, there may also be ways for SSH scholars to engage in normative intervention contexts without committing themselves to a particular normative direction; i.e., one may not necessarily strive to contribute to any particular direction of change (see for example [33]). However, we constructed this role framework to reflect on the role synergies and conflicts that we experienced as SSH researchers who do have a normative orientation towards the democratization of the R\&I system, and therefore, we chose to work with the incremental-radical axis.

The two different axes produce four different dimensions in our role landscape: (1) the analyticengaged dimension, (2) the analytic-consultative dimension, (3) the transformative dimension, and (4) the pragmatic dimension. In line with Wynne [34] and Chilvers [20], who criticize the use of clear-cut distinctions between roles and sharply delineated role worlds, we emphasize that the boundaries between the role landscape's dimensions are blurred and that the different dimensions also affect each other. 


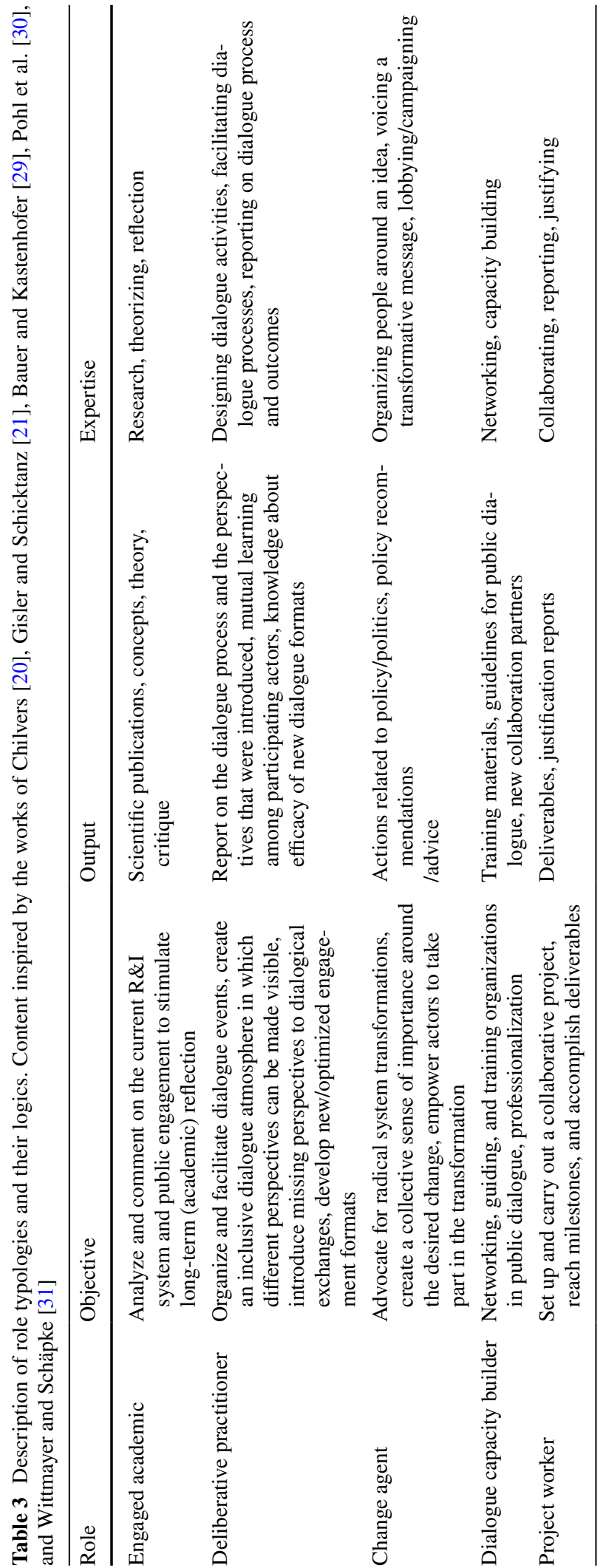


The Role Typologies

The general role landscape provides SSH scholars in normative intervention contexts with a basic structure that they can use to think about the specific roles they take on in their work, as well as the way in which these roles relate to each other. In this section, we employ relevant literature to distinguish between five specific role typologies that we adopted, simultaneously or at different moments, during our time in the NANO2ALL project (Table 3), and position them in the landscape. Here we conceptually understand each role in terms of its socio-political orientation in the normative intervention context (i.e., the type of contribution that is strived for-including associated tasks, activities, objectives, and outputs-and the degree of change that is aspired). Below, we briefly elaborate on these typologies and their position in the role landscape.

\section{The Engaged Academic}

The engaged academic - a role that we borrow from Bauer and Kastenhofer [29] — inhabits the analyticengaged dimension of the role landscape and is mainly focused on analyzing, theorizing, critiquing, and reflecting on current practices and processes without eschewing questions about the broader system in which these practices and processes are embedded. Engaged academics see the field of public engagement as a resourceful environment to empirically study the socio-political nature of science, technology, and their governance [29]. They have a normative commitment to a particular type of change (e.g., democratization of R\&I governance) and aspire to contribute to such change via their academic work. For example by introducing new categories and questions or-more generally speaking-holding up a mirror to current systems and practices [23, p.6]. Their mode of influence is thus focused on a form of "enlightment." Engaged academics see interaction with the academic community (via conferences, academic publications) and "outreach" as the most suitable means to contribute to long-term reflection and to changing discourses on science and technology in society [29]. Note that as opposed to the change agent (see description below), the engaged academic works as practice/policy outsider and seeks to maintain academic autonomy.

\section{The Deliberative Practitioner}

This role title was used by Bauer and Kastenhofer [29] and resembles Chilvers' [20] "practitioner," Wittmayer and Schäpke's [31] "process facilitator," Pohl et al.'s [30] and Escobar et al.'s [35] "facilitator," Gisler and Schicktanz's "reformer," [21], Radstake et al.'s "dialogue practitioner" [25], and Escobar et al.'s [35] “deliberative facilitator." In our framework, the deliberative practitioner is located on the border between the consultative-analytic and pragmatic dimension of the landscape and is someone who organizes and facilitates public engagement or activities involving dialogue. Deliberative practitioners shape and structure conversations between different actors [29, 35]. They keep the participants focused on the task set for the engagement event but take a neutral stance in the sense that they provide each participant with an equal opportunity to contribute and express themselves [29, 35]. Deliberative practitioners are thus focused on creating a respectful and inclusive environment to stimulate mutual learning among participants and possibly identify steps that can be taken toward achieving the relevant goal $[30,35]$. The additional tasks that deliberative practitioners carry out include (1) the use of analytical skills to report on the different perspectives that have been expressed in the dialogical exchange [29] and (2) the development of new methodologies and formats for dialogue [20, 21]. These new and improved methodologies mainly contribute to more pragmatic problem-solving steps that can be taken within current R\&I structures instead of transforming the existing system [21].

\section{The Change Agent}

The change agent is a role title that we borrow from Wittmayer and Schäpke [31]. They present the change agent as someone who actively participates in the search for solutions to the challenges at hand, empowering actors to undertake action, and creating a general "sense of importance" (p.489). In our framework, we position the change agent a little more sharply as someone who advocates for more radical transformations (as opposed to focusing on incremental changes within the boundaries of the existing system). Change agents do not shun involvement in political or policy processes to exert influence. They thus know how to 
voice a transformative message and feel a strong urge to lobby, campaign, or exert pressure in policy and political circles to promote change.

\section{The Dialogue Capacity Builder}

The dialogue capacity builder is a role partly inspired by Chilvers' [20] "coordinator of dialogue," and it encompasses, among other things, "networking, capacity-building and professionalization" of the public dialogue field (p.289). We position this role on the border between the pragmatic and transformative dimension of our framework. It is centered on optimizing current dialogue practices and enhancing the implementation of dialogue approaches. Such activities do not necessarily reject current structures or challenge the system (pragmatic dimension), but can contribute to more widespread capacity building that supports transformative change (transformative dimension). Dialogue capacity builders may present themselves as a representative of the public dialogue community, disseminate knowledge about dialogue methods and the theories that underpin them, and develop guidelines and training for those who would like to get involved in organizing public dialogue [20]. They thus empower other actors to organize and facilitate their own public engagement events.

\section{The Project Worker}

A role that is not frequently discussed as a separate entity in the employed literature on roles of the $\mathrm{SSH}$ scholar is the position of a project worker. This role tightly conforms to more structural conditions, of which the specifics may differ depending on the "world" (e.g. policy, academia, science communication practice) in which the SSH scholar operates. The role resembles that of "academic entrepreneur" or "scientific manager" (see for instance [36-39]) roles that have predominantly been conceptualized in the context of the natural sciences, but certainly have their parallels in the SSH. These roles have become more significant in our current knowledge economy, in which projects on research and innovation are increasingly supposed to yield measurable impact in relation to pre-set goals. The reality of EU projects like NANO2ALL is that they are structurally grounded in a bureaucratic, short-term logic-the socalled projectification in the public sector [40]. This structural condition invites for highly specific project and role perceptions, which may prioritize shortterm project management over both project content or project connection to goals with longer time horizons. It is for this reason that we treat the project worker as a separate role, having its own internal logic that unmistakably contributed to some of the role tensions that we experienced in our work. Project workers create workable relationships with other project partners, accomplish project milestones and deliverables on time, report on project outcomes, and are able to show that the funding received has been spent responsibly and effectively. We positioned the project worker in the pragmatic corner of the role landscape, because of the NANO2ALL's action- and policy-oriented character. As project workers, we also needed to be pragmatic in shaping project activities to fit the current funding requirements and evaluative standard of the European Union.

Although we attributed specific tasks and orientations to each of the five role typologies, these inherently become integrated into and entangled in the practice of public engagement initiatives or RRI projects, such as NANO2ALL in our case. The interventionist processes that are part of public engagement initiatives are complex and are oriented toward actions relating to policy; they require SSH scholars to embody multiple roles. Depending on the specific task and situation at hand, the SSH scholar may want to draw more heavily on one particular role than another [31]. Evidently, it is the specific context in which the SSH scholar operates that determines whether and how different roles complement or clash with each other in practice.

\section{Role Conflicts and Synergies}

In this section, we explore the consequences of role integration and entanglement in more detail based on our experiences in the NANO2ALL project. First, we outline some of the role synergies that we experienced as SSH scholars and then describe five challenges that we encountered that were caused by role conflict. We will reflect on the project's context, our own actions, and the various role logics that intersected these at certain points in time. 
Role Synergies

Throughout the NANO2ALL project, we experienced, in various ways, how the different roles we adopted could complement or strengthen each other. Here we highlight two prominent synergies that help to (1) enrich dialogue theory and practice and (2) create an experimentation and discussion space for a greater level of change.

\section{Enriching Dialogue Theory and Practice}

The overall goal of the NANO2ALL project was to contribute to the establishment of RRI governance of nanotechnologies in which inclusive participatory approaches and public dialogue play a central role. This is a complex and multifaceted task. It requires a comprehensive approach that is sensitive to theory and practice and is able to stimulate development on both of these levels. In our NANO2ALL project, we experienced how the combining of our roles as engaged academics, deliberative practitioners, and dialogue capacity builders could work synergistically to strengthen dialogue or RRI theory and practice.

With respect to strengthening practice, we could systematically integrate socioscientific insights into the design and execution of our NANO2ALL dialogue methodologies and could inspire and train other (potential) practitioners to integrate socioscientific insights into their dialogue work. For instance, when we designed our NANO2ALL dialogue formats (deliberative practitioner), we responded to socioscientific critiques (engaged academic) on persistent routines within public engagement practice, such as the emphasis on abstract reasoning, the cognitive exchange of arguments, and the favoring of expert knowledge over lay knowledge in many dialogue events [41, 42]. We developed playful and contextualized reflection exercises to create space for alternative forms of expression and learning and used various strategies to prevent unproductive dynamics around lay-expert divides. When facilitating dialogue exercises (deliberative practitioner), we also considered that our analytical skills and reflective attitude toward discussion of R\&I governance (engaged academic) are helpful for disentangling various perspectives around the table or for introducing missing perspectives to encourage critical reflection among the participants.
Our practical work as both deliberative practitioners and dialogue capacity builders also enriched our work as engaged academics. The role combination allowed us to test theoretical ideals (or at least their translation into concrete exercises and activities) in practice, which shed light on the effectiveness of particular design choices and on the impact of additional influential factors (e.g., the micropolitics existing among participants, the dialogue facilitation style, the dialogue location, etcetera), as well as possible interactions between those factors. We also learned about the potential of existing infrastructures for dialogue. Some scholars see a role for science centers and museums as contributors to a culture of sustained dialogue about science and technology (see, for example, Bandelli and Konijn [43]). By closely collaborating with science centers in our roles as dialogue capacity builders during the NANO2ALL project, we gained valuable insights into the opportunities that science centers have and the barriers they have to overcome to carry out such a task. This helped us-in our roles as engaged academics - to further conceptualize the potential role of science centers in the public engagement landscape. The interaction between practical dialogue experiences (deliberative practitioner, dialogue capacity builder) and academic reflection thus prevents public engagement theory from becoming irrelevant to actual dialogue and governance practices $[2,25]$.

\section{An Experimentation and Discussion Space for a Greater Level of Change}

RRI is grounded in the desire for a transformative change that will lead to a more open and inclusive R\&I system. This is a big challenge that requires new institutional structures and a different attitude of all actors working in the R\&I system [12, 44]. Such a transformative change requires time, discussion, and experimentation [32, 45, 46]. Here we would like to highlight how combining the roles of engaged academic, change agent, and project worker could work synergistically to fuel change from within the current system.

As project workers in NANO2ALL, we obtained (financial) resources to experiment with public engagement approaches and to collaborate and exchange ideas with other actors in the field (e.g., nanoscientists, industry, NGOs, citizens, intermediaries). This provided us with an environment in which we could voice, test, and adapt the more radical ideas about change in science and 
technology governance that we strive for as engaged academics and change agents. Discussion in our project consortium, for example, once again showed the existing diversity in perspectives regarding the topics of RRI and public engagement. In a plenary consortium session in the first year of the project, we asked our partners what they considered to be the right impact of the project. The responses varied and ranged from raising awareness of the impact of nanotechnology on society and educating people about the potential of nanotechnologies to creating better and more acceptable nanotechnology products and raising awareness of the power of the voice of society. These varied goals-from the instrumental to the more transformative ones-encouraged us as SSH scholars to repeatedly voice the transformative message in which RRI was originally grounded in project meetings (change agent logics). We consider this to be an important task of the SSH scholar in more pragmatic project environments. It may help project consortia to remain critical of the activities that they are undertaking (engaged academic) and to push the continuous search for creative opportunities that are taken gradually to change the existing dynamics in the R\&I governance system from within - without losing sight of the RRI's bigger transformative goal (change agent). Moreover, academic reflections and the analyses that the SSH scholar makes in the role of engaged academic also provide relevant insights into current public engagement practices and science and technology governance that may help to steer change agent and project worker approaches.

\section{Role Conflicts}

Despite the synergistic potential of role integration, we also encountered various challenges in which conflicting role logics played out. Here we outline five of them: (1) facilitating dialogue, (2) valuing our dialogue formats, (3) dealing with different rationales in realizing change, (4) incentives and priority setting, and (5) integrating research and critical reflection into an action-oriented project context.

\section{Facilitating Dialogue: Clashes Between Participant Contributions and Our Own Assumptions}

A highly prominent challenge that we encountered in our work for NANO2ALL arose when we tried to relate ourselves as SSH scholars to the various perspectives on and assumptions about research and innovation that we encountered in the dialogue events. Here we experienced tension between our roles as engaged academics, deliberative practitioners, and change agents. This manifested itself quite prominently during the EU multistakeholder dialogue that we organized and facilitated in Brussels. Here, several participants made contributions to the conversation in which they, for example, stressed the neutrality of research and innovation or the need for more science education as a way to ensure public trust in nanotechnology. Such statements are at odds with some of the basic assumptions in which our public engagement work as SSH scholars is grounded. We base our beliefs on socioscientific insights that have shown that science and technology are value-laden and that providing more knowledge and information about technology does not necessarily lead to public trust (engaged academic). Evidently, we were aware that our assumptions are not necessarily shared by all actors in research and innovation governance. However, when confronted with participant perspectives that clashed with these basic assumptions of our own, we sometimes found ourselves confused about how we should respond when facilitating the conversations in the dialogue event.

On the one hand, we did not want to challenge participant contributions too strongly, as our main task was to create an inclusive environment in which all perspectives would be welcomed (deliberative practitioner logics). We could introduce our socioscientific insights as an alternative perspective-if none of the other participants would do so-or use our analytical skills to make the difference in assumptions visible and stimulate critical reflection (engaged academic logics complementing deliberative practitioner logics). Yet, reasoning from a deliberative practitioner and engaged academic perspective, we did not consider that convincing participants of a different viewpoint was part of our task. On the other hand, we did feel a strong urge to ensure that the policy recommen-dations resulting from this dialogue would not merely serve the status quo (change agent logics). References to technology's value neutrality and conversational emphasis on the need for science education seemed to obstruct that goal. Our change agent logic thus inclined us to intervene when such comments were made. In practice, this struggle resulted in some members of our facilitator team gravitating toward the logic of the deliberative practitioner 
and engaged academic (resulting in a welcoming conversational atmosphere but less explicit control over whether the input resonated with RRI's transformative character) while others leaned toward the logic of the change agent (preventing instrumental interpretations of RRI-which would exclude more radical suggestions for action-from dominating the conversation, but in one instance also resulting in an unproductive confrontation between facilitator and participants).

Evidently, the tension between the roles of engaged academic, deliberative practitioner, and change agent was strengthened by the fact that the EU dialogue topic (RRI and engagement of societal actors in specific) was one that we-as SSH scholars-have strong ideas about. It directed our change agent logics not solely toward the dialogue process (i.e., striving for a democratic process) but also toward the dialogue outcome (i.e., striving for recommendations that promote democratization). The tension also seemed to relate to the contrasting aims underlying the EU event itself, that is, dialogue on the one hand (mutual learning) and providing input for recommendations on the other (sparking action and change). For us, it raised questions about how inclusive our inclusive dialogue approach was and how one can balance the aim of mutual learning and exchange (deliberative practitioner) with setting into motion a more radical change in our thinking about science and technology governance (change agent).

\section{Valuing Our Dialogue Formats}

A second role tension that we experienced in the context of the NANO2ALL project relates to valuing some of our own dialogue formats. Here the logics of our roles as deliberative practitioners and dialogue capacity builders seemed to conflict with those of our engaged academic role. We will illustrate this by focusing on our citizen dialogue format. Our design of this format was guided by all three role logics. From a deliberative practitioner perspective, we wanted to create a format that was fun and that would allow citizens to shape and express their perspective on nanotechnology developments. From the perspective of a dialogue capacity builder, we wanted the format to be appropriate for the science center environment and transferable to the science center staff, who would be hosting the dialogue sessions.
From an engaged academic perspective, we wanted the format to trigger broader reflection on nanotechnology developments-opening up the discussion between participants to a wider range of perspectives. We tried to unite these logics in practice by creating a dialogue format that encouraged citizens to imagine a hypothetical object that is produced by nanotechnology in the future and its potential impact. Participants were provided with ambiguous input material (e.g., information cards, cards that aimed to provide visual inspiration, cards to stimulate thought about societal impact, and cards with application contexts) and engaged in prototyping and short story-writing exercises. The prototypes and stories would serve as material for collective reflection on participants' needs, concerns, and values with respect to nanotechnology developments.

Although there seemed to be a synergistic potential between the different role logics for our citizen dialogue events, our analysis of the dialogue sessions also brought a tension to the fore. The evaluation questionnaire showed that participants did indeed feel supported enough to shape and express their perspective on nanotechnology developments (deliberative practitioner logic), and many of the responses from science centers were enthusiastic, with some even indicating that the format had inspired them to change their communication approach with audiences or that they had used the methodology outside the project as well (with visiting student groups, for example) (dialogue capacity builder logic). However, after analyzing the dialogue transcripts and materials, we noticed that many of the fictional objects and stories were rather technologically optimistic in character and were not as ambiguous, rich, and layered as we had hoped for in the development phase. The reflection on broader socio-technical impacts often had to be triggered by dialogue facilitators during the plenary discussion of objects and stories. We were even concerned that our method could, without the careful guidance of dialogue facilitators, actually strengthen a technologically fixed attitude instead of resulting in a more reflexive stance toward technologies. It made us question how we, in our roles as engaged academics, related to the fictional objects and stories that we let participants produce. Did we consider them legitimate tools for reflection in public engagement contexts? Or were practical considerations made (e.g., making the activity fun, attractive, and matching 
to the playful environment of most science centers; employing deliberative practitioner and dialogue capacity builder logics) at the cost of what we had wanted to accomplish with the format in our roles as engaged academics?

\section{Realizing Change: Dealing with Different Rationales}

For SSH scholars in public engagement and RRI, change (i.e., toward increased democratization) in science and technology governance is a central tenet. During the project, we were confronted with tensions between our roles as engaged academics, change agents, and project workers in relating to that change. This tension resided in our striving for a more radical system change (engaged academic and change agent) via participation in a project that is still deeply entrenched in the logics of the current system with a strong tendency to only allow for incremental steps (project worker).

The NANO2ALL project was embedded in a European funding structure specific to the topic of Nanotechnologies, Advanced Materials and Productions (NMP) and focused on responsible nanotechnology. The funding structure and framing of the project have an instrumental logic to them; they seem to imply that technology is the point of departure and thus only allowed us to focus on the question "how can we do nanotechnology right?" instead of broader questions that leave more room for the exploration of alternative (nontechnological) solutions and directions of development. Moreover, NANO2ALL produced several policy advice documents (interim recommendations and the project's final roadmap) to feed the policymaking processes of the European Commission's NMP unit, but up to the time of writing it has remained unclear how these documents have actually impacted policy choices. It is for these reasons that critical voices have warned that institutionally funded programs, like ours, may merely end up as tools that are used to gain public acceptance of technological pathways that have already been outlined somewhere else [47-49]. Indeed, this logic already resonated through the text of our project's funding call [50], which stated, for example: "An essential element of a safe and responsible nanotechnology governance is an effective and informed dialogue with all stakeholders, enhancing public confidence in nanotechnologies" (p.43). Evidently, public acceptance of and confidence in nanotechnologies is not what we are striving for from an engaged academic and change agent perspective. The instrumental logic that one must employ in the role of project worker thus sits uncomfortably with the normative rationale (i.e., engagement is the right thing to do in the face of our democratic ideals) and the substantive rationale (engagement will lead to better decisions) for engagement that we more readily employ in our roles as engaged academics and change agents.

\section{Incentives and Priority Setting}

During one of the project events, we heard a participant informally proclaim that the dominant role of $\mathrm{SSH}$ scholars in public engagement projects could prevent the project from having an impact. For an SSH scholar, any outcome of a project activity may serve as valuable data that can be analyzed, processed, and included in an academic publication or system critique. According to this participant, such a focus on academic value makes academics less prone to fighting for policy changes and action-oriented projects less likely to achieve a political impact. Although we considered this comment somewhat too blunt and simplistic (see synergy section), it did trigger us to reflect on the conflicting incentives and priorities that we experienced toward the end of the project, particularly between our roles as engaged academics and change agents.

In NANO2ALL's final stages, we had finished the specific project deliverables that we were in charge of and were contributing to the project's end product: the roadmap. Although this roadmap focused on policy recommendations, it became increasingly uncertain what the actual policy impact of this document would be. Because we had little time and few resources left, we prioritized other activities, most importantly the publication of academic papers; we had a strong incentive to do this because of our academic position at the university (engaged academic logics). We must acknowledge that our incentive to publish academically and to contribute to long-term reflection in the field (engaged academic logics) did indeed become a more dominant force toward the end of the project and resulted in less effort from our side to have an immediate policy/political impact via the final project deliverable (i.e., the roadmapproject worker logics) or to make a sustained effort after the project had ended to make the recommendations 
visible at the EU level rather than having them end up in a drawer somewhere (change agent logics). Although scholarly analysis in socioscientific papers may in itself be relevant to policy-albeit more indirectly [34], our choices concerning prioritization do raise a question that has been posed by Burchell [24]: to what extent do "social scientists instrumentalize the work of policy and practitioner actors for their own scholarly purposes?" (p.58).

\section{Integrating Research and Critical Reflection into an Action-Oriented Project}

A final challenge we experienced during the NANO2ALL project was integrating research into the structures, timelines, and collaborations of the NANO2ALL project. The action-oriented character of the project implied that its deliverables and milestones were mainly targeted at the execution of dialogue activities in various countries, reporting on dialogue outcomes, and the formulation of policy advice. The project plan did foresee some scientific publications as output, but only as part of the project's communication strategy. In this sense, the task logics we had to adhere to in our roles as project workers (i.e., establish deliverables and milestones) resonated most clearly with the task logics of our roles as deliberative practitioners (i.e., develop methodologies, organize dialogues, and report on their outcomes) and dialogue capacity builders (i.e., developing the public engagement field by training staff at science centers and building their capacity to organize dialogue).

In some instances, this synergy came at the cost of activities that we would ideally have undertaken from an engaged academic perspective due to conflicting role logics regarding the type of analyses that needed to be performed. The dialogue data that we acquired via our collaborative approach with science centersfor example dialogue transcripts, notes, facilitators' reflections, and evaluation questionnaires-provided sufficient information to report on the dialogue outcomes (deliberative practitioner logics) and to craft policy recommendations (project worker logics). But from an engaged academic perspective, we wanted to perform an analysis of the dialogue on a deeper level, and we sometimes lacked the relevant data to do so. For example, from a engaged academic perspective, we would have preferred to make video recordings of all dialogue sessions to capture as much detail as possible with respect to the dialogue dynamics. However, from a deliberative practitioner perspective, creating an open space in which people felt safe to express themselves was the most important factor, and therefore, we felt that the presence of video cameras might not be a good idea. We thus chose to work with audiorecordings. This limited our ability to study our methodologies on a deeper level. As a consequence, we felt that our striving for a thorough research approach and the ability to write academic papers (engaged academic logics) was sometimes put under pressure by demands that we wanted to respond to in our more action-oriented roles (i.e., deliberative practitioner, dialogue capacity builder, and project worker).

\section{Discussion}

SSH scholars have inhabited an increasing number of roles in the field of science and technology governance over the past 30 years, blurring dichotomous role distinctions such as those between the theoretical and the practical, the involved and the detached, and between having a radical or an incremental focus, etcetera [2, 16, 20, 22]. We explored how the integration of various roles into one another may play out in the complex and messy practice of a public engagement project in a normative intervention context. Our reflections illuminate how the identity of an SSH scholar in such a context can be "multiple," "shifting," "fragmented," or even "schizophrenic"- to quote Zuiderent-Jerak and Jensen [51] (p.229). We reflected on the synergistic potential of role integration but also illustrated how and in what instances inherent tension between different roles produced dilemmas and trade-offs in our public engagementrelated work. Evidently, some roles could be combined more easily than others. For example, the roles of deliberative practitioner, dialogue capacity builder, and project worker had a rather similar orientation (see their position in the role framework) and therefore did not produce much conflict in practice when combined. The same holds for the combination of dialogue capacity builder and change agent, with both roles focusing on empowerment and being strongly action oriented. Role combinations thatdespite their synergistic potential-proved more challenging in our experience include the deliberative 
practitioner being combined with the change agent, the engaged academic with the change agent, and the project worker with the engaged academic. These roles all diverged more sharply in terms of orientation (i.e., position in the role framework) and assigned tasks.

It is important to note that the experienced level of role conflict was not solely determined by differences in role orientations or having responsibilities for different tasks; it also depended on the specificities of the context in which we operated. For example, the conflict in our roles as deliberative practitioners and change agents who were facilitating the EU stakeholder dialogue became particularly prominent because the topic of the dialogue was public engagement itself. Had we facilitated, say, a dialogue on innovation directions for nanotechnology (or any other technology), our opinions about the outcome of the dialogue would have been less pronounced and our urge to intervene from a change agent perspective would have focused mostly on the process of the dialogue (i.e., is it democratic?). The change agent logics may then have converged more smoothly with the deliberative practitioner logics in the specific context of dialogue facilitation. We thus stress that the precise benefits and trade-offs of role integration cannot be determined in the abstract but should be assessed and accounted for within the specific context in which the SSH scholar operates (also see [52] and [51] on attending to the situatedness of SSH scholars' roles and positions, or). This requires role awareness and reflexivity. They help the SSH scholar to see what may be at stake when he or she has to deal with multiple role logics in a particular situation and allow for more explicit consideration of his or her position and strategies that can be used to cope with any tension [31, 52].

In this paper, we have introduced a framework that may serve as a starting point for SSH scholars who wish to reflect on their role. Three remarks are relevant in this respect. First, our framework was constructed in a way that helped to articulate the synergies and tensions between the different roles we had as SSH scholars with a normative commitment in the project. Here one should note that the framework takes the desirability of democratization as a given and that variation in orientation to change exists solely in its degree of radicality (see $y$-axis of the role landscape, Fig. 2). Although for many SSH scholars the democratization ideal may indeed serve as a general point of departure for their public engagement-related work, it certainly does not reflect an ideal that is shared by all actors in science and technology governance, nor by all SSH scholars (see, for example, [32, 45]). This therefore makes the framework less adequate if one wants to draw connections with the role positions of other actors in the field or to explain the actions of SSH scholars that do not commit to a democratic ideal, but rather stay distanced, skeptical observers. It was beyond the scope of this paper to discuss how our democratization ideal conflicts with other ideals in research and innovation, yet such tensions evidently did arise.

Second, the five role typologies that we introduced via the role framework were chosen because of their fit with our own tasks and experiences in the NANO2ALL project. We would like to remind the reader that alternative role conceptualizations and role typologies (e.g., "voice of the public," "knowledge broker," and "translator") exist and have been described in the literature before [23, 29, 31, 53]. Which role typologies are most relevant for a reflexive exercise will depend on the specificities of a project, the engagement context, and the SSH scholars themselves.

Lastly, we would like to stress again that the logics of the different roles that we presented in this paper, as well as the way they become entangled in practice, dynamically intersect with broader institutional structures and conditions in academia and at European policy level. In our analysis, we for instance pointed at the influence of academic reward structures (i.e., the need to publish academically to build one's academic career) on how we prioritized certain activities over others. We also illustrated how European structures to promote socio-technical integration and public engagement (i.e., bureaucratic, short-term projects that aim for measurable outcomes in relation to predefined roles) push SSH scholars to take on certain roles (e.g., project worker), while making it more difficult to inhabit others (e.g. change agent). The character of existing roles and the ability of SSH scholars to adopt them in practice thus highly relies on the institutions these scholars need to relate to. 
The Desirablity of Role Integration

Our reflections may raise broader questions about the desirability of the type of role integration we have described in this paper. Should SSH scholars participate in policy action-oriented projects like ours and should they aspire to have such a multitude of roles in the public engagement field at all? Over the years, concerns have been expressed about SSH scholars who take on more pragmatic and action-oriented roles that are sponsored by science policy institutions such as those funded by the European Union. Scholars may lose their critical distance and independence [24] and could end up merely as instrumental forces for dominant technocratic regimes and existing power structures [20, 34, 52, 54]. Are SSH scholars who want to close the gap between public engagement processes and actual impact on R\&I policy and practice institutionally required to slip into roles that do not eliminate this gap, but dynamically stabilize it? Are we naively creating a situation in which academics receive funds to happily present themselves as change agents or engaged academics for scholarly prestige, while unwittingly reproducing the very system dynamics that they say they want to see changed? How realistic is the actual transformative promise of RRI considering its embedment in an innovation system that is dominated by market competitiveness, economic growth, and industry interests? [14]. We contend that such concerns are real and that they echoe some of the role dilemmas that we outlined in this paper (i.e., "realizing change" and "incentives and priority setting"). Action-oriented SSH scholars in RRI programs and beyond may indeed fall prey to larger power games beyond their control—despite good intentions. Such dynamics deserve serious attention and scrutinizing, particularly at institutional level.

At the same time, voices - inside and outside academia - claim that solely commenting from the sideline does not yield much in terms of actual change either. Various reasons have been put forward as to why SSH scholars should experiment with action-oriented roles. They include-among others - the ability to move theoretical notions and ideals into practice with resulting tentions potentially helping to identify new approaches, routes, and strategies to public engagement [2], the increased ability of SSH analyses to "land in" actual "dialogue and engagement practices" [25, p.46], the possibility to produce knowledge that is perceived as relevant by actors outside academia [55], the opportunity to put the "social and intersubjective nature" of the SSH field to use in helping to "bridge divides between publics and political authorities" [18, p.15], and the opportunity to stimulate collective reflection on practices with the actors that are able to make actual changes [55].

We would also like to note that the continuing professionalization of the public engagement field asks for reflexive learning in practice [20, 56], something that SSH scholars with an integrated role profile may be able to stimulate in policy and practice contexts. With public engagement gaining momentum, a whole new and professionalized industry has emerged around the concept, extending far beyond the activities of SSH scholars. Public engagement has become marketable service, sometimes at the detriment of democratic impact $[20,57]$. Our reflections in this paper have shown that, as actionoriented SSH scholars in public engagement, we are just as much part of such market-driven dynamicsi.e., also in need of funding to do our work and develop professionally. However, we agree with Chilvers [56] and Wilkinson [22] that also being embedded in an academic institution and community that encourages critique, reflection and skepticism allows for more (institutional) space to take on the reflexive stance that is now called for amongst practitioners $[3,20,56,58]$. These reflections from scholars as practice insider may not only be valuable to the academic community working on questions regarding public engagement, but may particularly be worth sharing and discussing in policy institutions and among practitioner communities-e.g., professional facilitators, engagement consultants, science communicators, NGOs, natural scientists-who may take on roles that are similar to some of the ones we have presented in our framework. This does require SSH scholars to actively engage with such communities and clearly communicate the relevance of their reflexive work to a broader audience $[59,60]$.

The above described concerns and opportunities demonstrate the need for continued discussion on the if, when, how, and why of SSH scholars adopting multiple roles in public engagement. Most pertinently, we should ask ourselves the question under what structural and institutional conditions role integration may 
contribute to actual change. This paper has elaborated on one example of role integration and has outlined the tensions it may raise. The actual impact of role integration in this field - in terms of changeremains a contentious topic that would require more comprehensive evaluation studies. For now, the very least we can ask of SSH scholars that integrate multiple roles is to be reflexive and skillful in doing so.

\section{Toward Reflexive and Skillful Role Integration}

We have shown that role integration does not come without challenges or tension. For those scholars who want to combine roles in normative intervention contexts, it is important to attend to several aspects of doing so. First, we again stress the importance of role awareness and reflexivity to navigate role dilemmas. The benefits and trade-offs of particular role combinations need to be assessed within the specific context of their use. In particular situations, one may, for example, decide not to take on a certain role or, more explicitly, may decide to divide the conflicting roles among multiple people within a project consortium or social scientist team [31]. We argue that careful consideration of roles and potential conflict should take place as early as possible in a project or collaboration, when its design can still be adapted to a certain extent [31]. We are aware that it is impossible to fully plan one's role position in advance-Pohl et al. [30] and Wittmayer and Schäpke [31] remind us that the uptake of a role in a particular instance does not constitute a purely rational act but also depends on the situation at hand and one's experience, competencies, and personality. In addition, structural conditions under which one works may limit the freedom to choose or reject certain roles (see our earlier remark). Therefore, reflection on the influence of different role logics on research and engagement work should continue throughout the entire collaborative process. With the inevitable presence of tension, the least we can do is be transparent about it and consider the impact of trade-offs that have to be made [52].

Second, we want to draw attention to the wide variety of skills and competencies that SSH scholars with an integrated role profile need to possess. After all, being a good engaged academic does not automatically imply that one is able to effectively organize and facilitate dialogue sessions, just to mention one example.
The latter requires social and organizational skills that extend beyond what is usually taught in academic curricula [35]. Emery et al. [61] point to the influential role that individual public engagement practitioners may have and also highlight the importance of their "political capacity and awareness" to increasing the chance that public engagement output is actually integrated into decision-making processes (p. 439). Not much has been written about the competency and skill that are needed for the new roles of SSH scholars in R\&I governance. In this respect, we may learn from discussions in the field of process-oriented sustainability science or from those in action research and transdisciplinary research in general, where this topic has received more attention (see, for example, $[62,63]$ or the suggestions in [30]). New competency requirements not only relate to additional tasks (e.g., organizing and hosting workshops, shaping policymaking processes) but also to the role-integration work itself [63]. Finding one's way through the role landscape and dynamically balancing different commitments and attitudes requires certain "navigation skills." One may argue that practical experiences and a reflexive attitude will foster the development of such skills over time, but we plead that more is needed to safeguard the process qualities of both public engagement practices and scholarly work in this field. Specific educational programs and training opportunities may be needed for SSH scholars who wish to integrate a multitude of roles into their work on public engagement and science and technology governance. We call for a broader discussion on what it would take to prepare such scholars for and guide them in this complex navigation task.

Lastly, role integration would also need to be valued and supported institutionally to enhance its chances of societal impact. As long as SSH scholar's impact is merely assessed in terms of academic publications within academia, the ability to contribute to actual change remains marginal. Similarly, (material) structures at European level should be scrutinized for the types of roles they create and close down for SSH scholars who want to bridge the gap between the social and the technical. Inviting SSH scholars to work on socio-technical integration within structures that remain disconnected from actual influence on R\&I policy or practice obstruct the accomplishment of systemic changes that are discursively promoted at European level. 
After 20 years of public engagement with nanotechnology, other emerging technologies, such as artificial intelligence, are gaining public interest. In this context, SSH scholars will meet new opportunities to develop the public engagement field and will encounter challenges while trying to do so. Upcoming funding programs, such as the Horizon Europe program, may invite SSH scholars to take up new roles or role combinations. Our framework may serve as a valuable tool for exploring these roles and for articulating their (im)possibilities, synergies, and inherent tensions. This may not only help scholars to better understand, assess, and communicate about their own position in the public engagement field, but could also be a starting point for deeper exploration of the relevance of institutions in the making and taking of roles. Such efforts are crucial in a context in which so many interests, values, perspectives, and understandings compete to shape research and innovation governance.

Acknowledgements We are grateful for the helpful comments and suggestions that we received from both the special section guest editors Franz Seifert and Camilo Fautz and the two anonymous reviewers of this paper, which helped us sharpen and enrich our manuscript.

Funding This research took place in the context of the NANO2ALL project. This project has received funding from the European Union's Horizon 2020 research and innovation program under grant agreement no 685931. This document reflects only the author's view and the Commission is not responsible for any use that may be made of the information it contains.

Open Access This article is licensed under a Creative Commons Attribution 4.0 International License, which permits use, sharing, adaptation, distribution and reproduction in any medium or format, as long as you give appropriate credit to the original author(s) and the source, provide a link to the Creative Commons licence, and indicate if changes were made. The images or other third party material in this article are included in the article's Creative Commons licence, unless indicated otherwise in a credit line to the material. If material is not included in the article's Creative Commons licence and your intended use is not permitted by statutory regulation or exceeds the permitted use, you will need to obtain permission directly from the copyright holder. To view a copy of this licence, visit http://creativecommons.org/licenses/by/4.0/.

\section{References}

1. Wilsdon J, Willis R (2004) See-through science: Why public engagement needs to move upstream. Demos, London
2. Delgado A, Lein Kjolberg K, Wickson F (2010) Public engagement coming of age: From theory to practice in STS encounters with nanotechnology Public Underst Sci 1-20. https://doi.org/10.1177/0963662510363054

3. Stilgoe J, Lock SJ, Wilsdon J (2014) Why should we promote public engagement with science? Public Underst Sci 23:4-15. https://doi.org/10.1177/0963662513518154

4. Krabbenborg L, Mulder HAJ (2015) Upstream public engagement in nanotechnology. Sci Commun 37:452-484. https://doi.org/10.1177/1075547015588601

5. Hagendijk R, Irwin A (2006) Public deliberation and governance: Engaging with science and technology in contemporary Europe. Minerva 44:167-184. https://doi.org/ 10.1007/s11024-006-0012-x

6. BurriRV(2018)Models of publicengagement:Nanoscientists' understandings of science-society interactions. NanoEthics 12:81-98. https://doi.org/10.1007/s11569-018-0316-y

7. Macnaghten P, Kearnes MB, Wynne B (2005) Nanotechnology, governance, and public deliberation: What role for the social sciences? Sci Commun 27:268-291. https://doi. org/10.1177/1075547005281531

8. Rogers-Hayden T, Mohr A, Pidgeon N (2007) Introduction: Engaging with nanotechnologies - engaging differently? NanoEthics 1:123-130. https://doi.org/10.1007/ s11569-007-0013-8

9. Barben D, Fisher E, Selin C, Guston DH (2008) Anticipatory governance of nanotechnology: Foresight, engagement, and integration. In: Hackett E, Lynch M, Wajcman J (eds) The handbook of science and technology studies, 3rd edn. MIT Press, Cambridge, pp 979-1000

10. Guston DH (2014) Understanding "anticipatory governance”. Soc Stud Sci 44:218-242. https://doi.org/10.1177/ 0306312713508669

11. Guston DH, Sarewitz D (2002) Real-time technology assessment. Technol Soc 24:93-109

12. Owen R, Macnaghten P, Stilgoe J (2012) Responsible research and innovation: From science in society to science for society, with society. Sci Public Policy 39:751760. https://doi.org/10.1093/scipol/scs093

13. Von SR (2013) A vision of responsible research and innovation. In: Owen R, Bessant J, Heintz M (eds) Responsible innovation: Managing the responsible emergence of science and innovation in society. Wiley, Chichester, pp 51-74

14. de Saille S (2015) Innovating innovation policy: The emergence of 'Responsible Research and Innovation'. J Responsible Innov 2:152-168. https://doi.org/10.1080/ 23299460.2015.1045280

15. Ribeiro BE, Smith RDJ, Millar K (2017) A mobilising concept? Unpacking academic representations of Responsible Research and Innovation. Sci Eng Ethics 23:81-103. https://doi.org/10.1007/s11948-016-9761-6

16. Schulz-Schaeffer I, Weyer R, Johannes W (2009) Editorial: The new role(s) of social sciences Since. Sci Technol Innov Stud 5:3

17. Jasanoff S (2004) The idiom of co-production. In: Jasanoff $\mathrm{S}$ (ed) States of knowledge: The co-production of science and social order. Routledge, London, pp 1-12

18. Papanagnou G (2011) Building bridges? The challenges of social science for policy. In: Papanagnou G (ed) Social 
science and policy challenges - democracy, values and capacities. UNESCO Publishing, Paris, pp 7-23

19. Steinmetz G (2018) Scientific autonomy, academic freedom, and social research in the United States. Crit Hist Stud 5:281-309. https://doi.org/10.1086/699925

20. Chilvers J (2012) Reflexive engagement? Actors, learning, and reflexivity in public dialogue on science and technology. Sci Commun 35:283-310. https://doi.org/10.1177/ 1075547012454598

21. Gisler P, Schicktanz S (2009) Introduction: Ironists, reformers, or rebels? Sci Technol Innov Stud 5:5-17. https://doi. org/10.17877/DE290R-8460

22. Wilkinson $C$ (2014) Engaging with strangers and brief encounters. Bull Sci Technol Soc 34:63-76. https://doi. org/10.1177/0270467614552841

23. Abels G (2009) Organizer, observer, participant. Sci Technol Innov Stud 5:19-35

24. Burchell K (2009) A helping hand or a servant discipline? Sci Technol Innov Stud 5:49-61

25. Radstake M, Nelis A, van den Heuvel-Vromans E (2009) Mediating online DNA-dialogues: From public engagement to interventionist research. Sci Technol Innov Stud $5: 37-47$

26. NANO2ALL (2019) What we do. http://www.nano2all.eu/ what-we-do/\#1547728929137-b65adac9-4fe7. Accessed 8 Oct 2019

27. Burget M, Bardone E, Pedaste M (2017) Definitions and conceptual dimensions of Responsible Research and Innovation: A literature review. Sci Eng Ethics 23:1-19. https://doi.org/10.1007/s11948-016-9782-1

28. Stilgoe J, Owen R, Macnaghten P (2013) Developing a framework for responsible innovation. Res Policy 42:1568-1580. https://doi.org/10.1016/j.respol.2013.05. 008

29. Bauer A, Kastenhofer K (2018) Policy advice in technology assessment: Shifting roles, principles and boundaries. Technol Forecast Soc Change. https://doi.org/10.1016/j. techfore.2018.06.023

30. Pohl C, Rist S, Zimmermann A et al (2010) Researchers' roles in knowledge co-production: Experience from sustainability research in Kenya, Switzerland, Bolivia and Nepal. Sci Public Policy 37:267-281. https://doi.org/10. 3152/030234210X496628

31. Wittmayer JM, Schäpke N (2014) Action, research and participation: Roles of researchers in sustainability transitions. Sustain Sci 9:483-496. https://doi.org/10.1007/ s11625-014-0258-4

32. Hartley S, Pearce W, Taylor A (2017) Against the tide of depoliticisation: The politics of research governance. Policy Polit 45:361-377. https://doi.org/10.1332/ 030557316X14681503832036

33. Zuiderent-Jerak T (2015) Situated intervention: Sociological experiments in health care. MIT Press, Cambridge

34. Wynne B (2007) Dazzled by the mirage of influence? Sci Technol Hum Values 32:491-503. https://doi.org/10.1177/ 0162243907301086

35. Escobar O, Faulkner W, Rea HJ (2014) Building capacity for dialogue facilitation in public engagement around research. J Dialogue Stud 2:87-111

36. Fogelberg H, Lundqvist MA (2013) Integration of academic and entrepreneurial roles: The case of nanotechnology research at Chalmers University of Technology. Sci Public Policy 40:127-139. https://doi.org/10.1093/scipol/scs074

37. Shelley L (2010) Uncovered: Changing roles and 'shifting arenas ' in the academy. High Educ Q 64:41-64. https:// doi.org/10.1111/j.1468-2273.2009.00429.x

38. Dunleavy K, Noble M, Andrews H (2019) The emergence of the publicly engaged research manager. Res All 3:105-124

39. Jain S, George G, Maltarich M (2009) Academics or entrepreneurs? Investigating role identity modification of university scientists involved in commercialization activity. Res Policy 38:922-935. https://doi.org/10.1016/j.respol.2009. 02.007

40. Godenhjelm S, Lundin RA, Sjöblom S (2015) Projectification in the public sector - the case of the European Union. Int J Manag Proj Bus 8:324-348. https://doi.org/10.1108/ IJMPB-05-2014-0049

41. Selin C, Rawlings KC, de Ridder-Vignone K et al (2017) Experiments in engagement: Designing public engagement with science and technology for capacity building. Public Underst Sci 26:634-649. https://doi.org/10.1177/ 0963662515620970

42. Davies SR, Selin C, Gano G, Pereira ÂG (2012) Citizen engagement and urban change: Three case studies of material deliberation. Cities 29:351-357. https://doi.org/10. 1016/j.cities.2011.11.012

43. Bandelli A, Konijn EA (2012) Science centers and public participation: Methods, strategies, and barriers. Sci Commun 35:419-448. https://doi.org/10.1177/ 1075547012458910

44. Rip A (2014) The past and future of RRI. Life Sci Soc Policy 10:1-15. https://doi.org/10.1186/s40504-014-0017-4

45. van Hove L, Wickson F (2017) Responsible research is not good science: Divergences inhibiting the enactment of RRI in nanosafety. NanoEthics 11:213-228. https://doi.org/10. 1007/s11569-017-0306-5

46. Delgado A, Åm H (2018) Experiments in interdisciplinarity: Responsible Research and Innovation and the public good. PLoS Biol 16:1-8. https://doi.org/10.1371/journal. pbio. 2003921

47. Irwin A (2006) The politics of talk: Coming to terms with the "new" scientific governance. Soc Stud Sci 36:299-320. https://doi.org/10.1177/0306312706053350

48. Powell MC, Colin M (2008) Meaningful citizen engagement in science and technology: What would it really take? Sci Commun 30:126-136. https://doi.org/10.1177/ 1075547008320520

49. Braun K, Könninger S (2018) From experiments to ecosystems? Reviewing public participation, scientific governance and the systemic turn. Public Underst Sci 27:674-689. https://doi.org/10.1177/0963662517717375

50. EC (2013) HORIZON 2020 - work programme 2014-2015

51. Zuiderent-Jerak T, Bruun Jensen C (2007) Editorial introduction: Unpacking 'intervention' in science and technology studies. Sci Cult (Lond) 16:227-235. https://doi.org/10. 1080/09505430701568552

52. Oudheusden M, Laurent B (2013) Shifting and deepening engagements. Sci Technol Innov Stud 9:3-22

53. Turnhout E, Stuiver M, Klostermann J et al (2013) New roles of science in society: Different repertoires of knowl- 
edge brokering. Sci Public Policy 40:354-365. https://doi. org/10.1093/scipol/scs114

54. Donovan C (2005) The governance of social science and everyday epistemology. Public Adm 83:597-615. https:// doi.org/10.1111/j.0033-3298.2005.00464.x

55. Langenhove L (2011) Social sciences and policy impact: The case for a participatory approach. In: Social science and policy challenges - democracy, values and capacities \& policy. pp 95-112

56. Chilvers J (2010) Sustainable participation? Mapping out and reflecting on the field of public dialogue on science and technology

57. Bherer L, Gauthier M, Simard L (2017) The professionalization of public participation. Routledge, New York

58. Voß JP, Amelung N (2016) Innovating public participation methods: Technoscientization and reflexive engagement. Soc Stud Sci 46:749-772. https://doi.org/10.1177/ 0306312716641350

59. Cassidy A (2008) Communicating the social sciences. In: Bucchi M, Trench B (eds) Routledge handbook of public communication of science and technology. Routledge, London, pp 186-197
60. Salmon RA, Priestley RK, Goven J (2017) The reflexive scientist: An approach to transforming public engagement. J Environ Stud Sci 7:53-68. https://doi.org/10.1007/ s13412-015-0274-4

61. Emery SB, Mulder HAJ, Frewer LJ (2015) Maximizing the policy impacts of public engagement: A European study. Sci Technol Hum Values 40:421-444. https://doi.org/10. 1177/0162243914550319

62. Wiek A, Withycombe L, Redman CL (2011) Key competencies in sustainability: A reference framework for academic program development. Sustain Sci 6:203-218. https://doi.org/10.1007/s11625-011-0132-6

63. Levin M (2012) Academic integrity in action research. Action Res 10:133-149. https://doi.org/10.1177/1476750312445034

Publisher's Note Springer Nature remains neutral with regard to jurisdictional claims in published maps and institutional affiliations. 